\title{
On the Origin of the Conformationally Non-Interconvertable Isomers of Bisphenyldirhodium(III) Caprolactamate
}

\author{
Jian-Hua Xie and Michael P. Doyle* \\ Department of Chemistry and Biochemistry, University of Maryland, College Park, Maryland 20742, U.S.A. \\ Dedicated to the memory of Ernest L. Eliel
}

Received July 11, 2009; accepted September 24, 2009

\begin{abstract}
A plausible explanation for the unprecedented formation of two conformational isomers of bisphenyldirhodium(III) caprolactamate is presented. The presence of acetic acid during the coupling process leading to the formation of bisphenyldirhodium(III) caprolactamate is shown to increase the propeller conformer at the expense of the biplanar conformer, Acetic acid is also found to catalyze the decomposition of bisphenyldirhodium(III) caprolactamate with the propeller conformation reacting at a rate that is more than ten times greater than that for the biplanar conformation. We speculate that protonation of one of the caprolactamate ligands changes the orientation of the phenyl ring in its approach to rhodium in the product-forming step of the arylation reaction leading to the formation of the two conformational isomers.

Key words: Rhodium, Conformational Isomers, Acetic Acid, Phenylrhodium, Coupling.
\end{abstract}

\section{Introduction}

Much of our understanding of conformational analysis is derived from the authorship of Ernest Eliel who, from his own investigations and reviews of the known literature, clarified our knowledge of conformations in organic molecules [1]. As conformation is one component of organic stereochemistry, Eliel established what most regard as the definitive treatise in the area in 1994 [2], and I had the privilege to work with the master in preparing the abridged version [3]. Based on the ongoing interests of my research group in dirhodium compounds and their chemistries [4-6], we have recently investigated higher oxidation states of dirhodium carboxamidates one aspect of which is intimately related to conformational analysis and organic stereochemistry, and we have selected a feature of this work to honor Ernest Eliel's memory.

We have reported the preparation and characterization of a thermally and chemically stable paddlewheel dirhodium(III) caprolactamate with phenyl substituents in the axial positions [7]. The general structural features of this compound have been described along with a thorough computational analysis of its associated energy levels [8]. In addition, a synthetic methodology to conveniently access these novel compounds was developed in which dirhodium(II) caprolactamate was treated with arylboronic acids in the presence of catalytic amounts of copper(II) sulfate to form variously substituted bisaryldirhodium(III) compounds in high yield [9].
Resumen. Se presenta evidencia sobre una posible explicación de la novedosa formación de dos isómeros conformacionales del complejo caprolactama bisfenildirodio(III). Se muestra que la presencia de ácido acético durante el proceso de acoplamiento conduce al incremento en la formación del complejo caprolactama bisfenildirodio(III) en su confórmero de propela a expensas del confórmelo biplanar. También se demuestra que el ácido acético cataliza la descomposición del complejo caprolactama bisfenildirodio(III) en su forma de propela a una rapidez diez veces mayor que el complejo en forma biplanar. Se especula que la protonación de uno de los ligantes caprolactamas cambia la orientación del anillo bencénico al acercarse al rodio durante la etapa de formación del producto en la reacción de arilación que conduce a los dos isómeros conformacionales.

Palabras clave: Rodio, isómeros conformacionales, ácido acético, fenilrodio, acoplamiento.

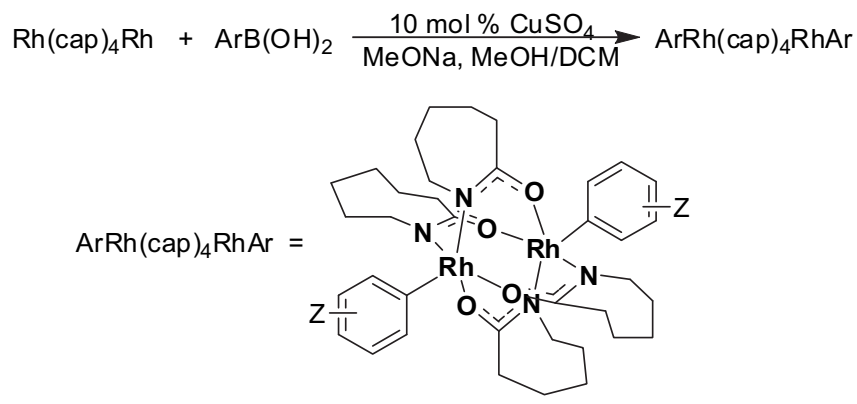

As we recently reported [10], in the course of these investigations we discovered a persistent second product as a minor contributor to the total isolated product. This compound, with the color of orange $(\mathbf{O})$ initially viewed by thin layer chromatography as a spot well separated from the major green product $(\mathbf{G})$, had the same constitution and configuration of the previously reported bisphenyldirhodium(III) caprolactamate. However, these two compounds were conformationally different, as can be seen in the depictions of their crystal structures in Figure 1. They are related to each other by converting two 7-membered rings from one side to another. The propeller-like conformer can conceptionally be obtained from the biplanar conformer by "flipping" two oppositely placed 7-membered rings. The transition state for this interconversion is necessarily related to conformational isomerization within the 7-member rings and was initially expected to be easily transgressed. 

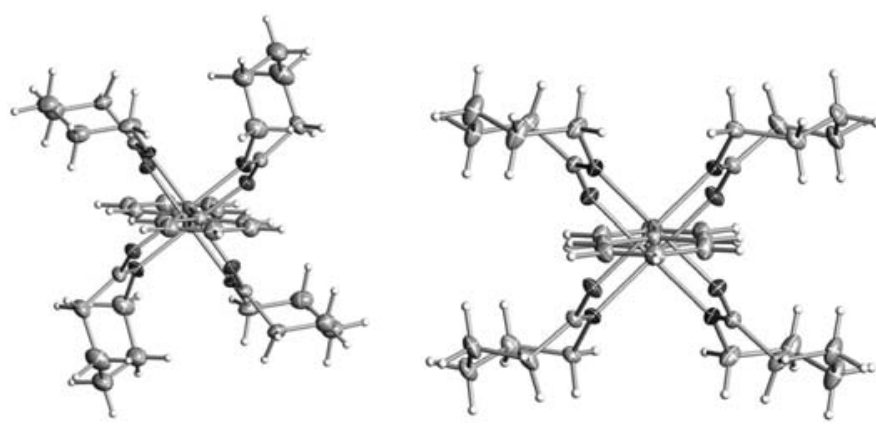

Fig. 1. The propeller conformation (left) and biplanar conformation (right) of bisphenyldirhodium(III) caprolactamate with view along the rhodium-rhodium axis. They differ from each other in the orientation of the bridging caprolactamate ligands.

\section{Results and Discussion}

As previously reported [10], heating either the propeller or the biplanar structure, as solids or in solution, to temperatures as high as $240^{\circ} \mathrm{C}$ (solid) or $130^{\circ} \mathrm{C}$ (refluxing chlorobenzene) did not cause any detectable interconversion. Dissolving the two structures in appropriate solvents, and obtaining their spectral and chromatographic data, showed that the two isomers were distinct and that the structural differences were not due to crystal packing effects. HPLC analysis of the two conformers that showed the propeller conformer eluting faster than biplanar conformer (Fig. 2) is consistent with their expected behavior based on size exclusion. Computational analyses [10] did not provide an understanding of the unexpected energy barrier that exists between these two conformational isomers.

As the biplanar conformer and the propeller conformer are not interconvertable, what is their origin? The reactant, dirhodium(II) caprolactamate, is a structurally well-established framework that has previously shown no evidence for conformational isomers [11]. Relying on evidence relating to the methodology used for ligand exchange in the formation of dirhodium(II) caprolactamate [12] from dirhodium(II) acetate, we suspected that acetic acid in the reactant dirhodium(II)

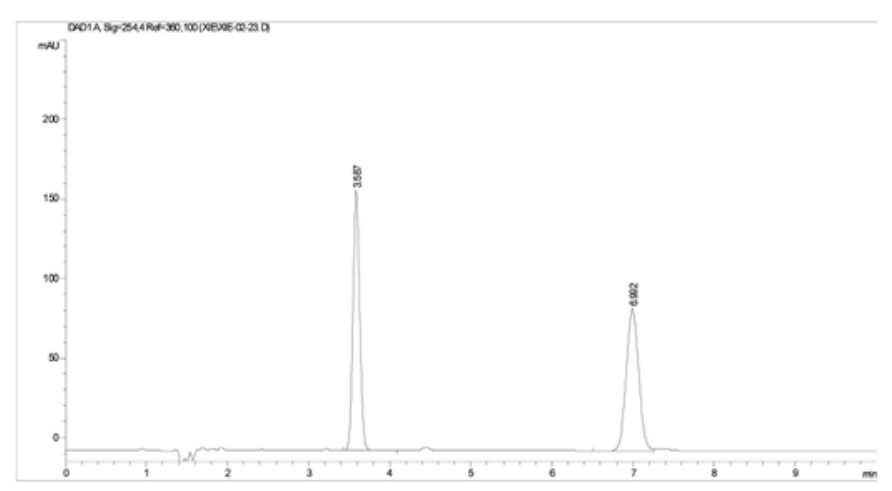

Fig. 2. HPLC of a solution of a mixture of the propeller and biplanar conformers (eluent of ${ }^{i} \mathrm{PrOH}: \mathrm{MeCN}=13: 87$ on a $15 \mathrm{~cm}$. C-18 column). The propeller conformer elutes first. caprolactamate used to produce the major green product might be responsible for the formation of the propeller conformer, and we set out to examine this hypothesis by performing the synthesis of dirhodium(II) caprolactamate under identical conditions using controlled amounts of acetic acid in refluxing toluene, followed by subjecting the isolated dirhodium(II) material to standard oxidative conditions for the synthesis of bisphenyldirhodium(III) caprolactamate. In the absence of acetic acid, the amount of the propeller conformer obtained was less than $3 \%$, and as the amount of acetic acid was increased so did the amount of the propeller conformer to a limiting amount. The outcome of this study is seen in Fig. 3 which clearly shows that the presence of acetic acid during the synthesis of dirhodium(III) caprolactamate causes the diversion of product to the propeller conformer $(\mathbf{O})$ at the expense of the biplanar conformer $(\mathbf{G})$. The decrease in yield of total amount of bisphenyldirhodium(III) caprolactamate, however, is due to the exchange of acetate for caprolactam that produces dirhodium(II) compounds with 1-3 caprolactam ligands. In these studies we could not discern chromatographically any difference in dirhodium(II) tetrakis(caprolactamate), although by NMR there is a signal for acetate that is not due to dirhodium(II) compounds with 1-3 caprolactam and 3-1 acetate ligands. The role of acetic acid in the formation of $\mathbf{O}$ is uncertain, but it is clearly associated with the set of coordination events that occur prior to or during the conversion of dirhodium(II) caprolactamate to bisphenyldirhodium(III) caprolactamate. One explanation may be that protonation of one of the caprolactamate ligands changes the orientation of the phenyl ring in its approach to rhodium in the product-forming step of the arylation reaction Scheme 1). ${ }^{8}$

As acetic acid contributes to the formation of $\mathbf{O}$, so also is it responsible for its destruction. Acid promoted destruction of

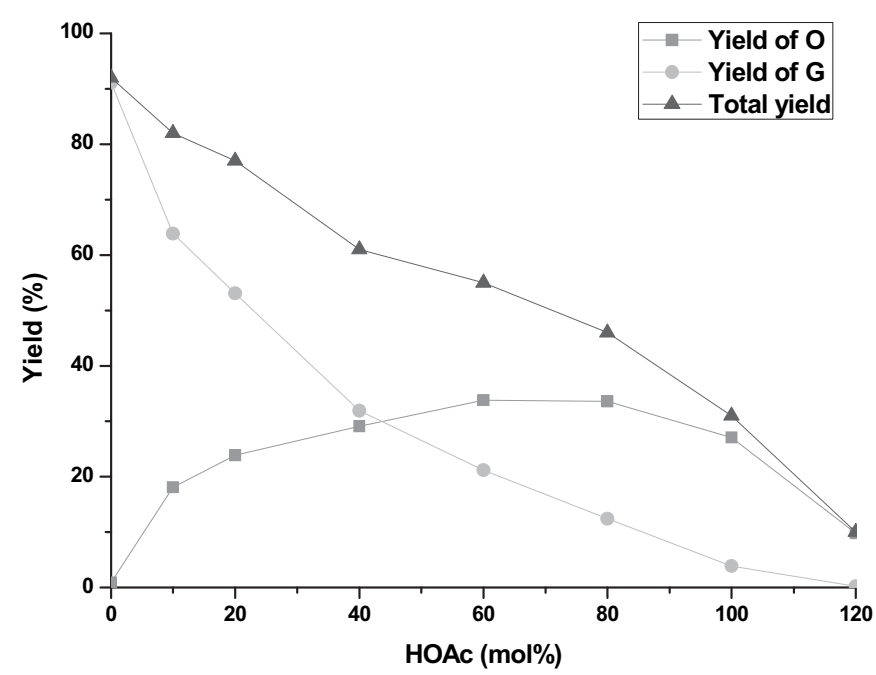

Fig. 3. Relative yield of $\mathbf{O}$ and $\mathbf{G}$ and total isolated yield of $(\mathbf{O}+\mathbf{G})$ from the copper(II) catalyzed reaction of dirhodium(II) caprolactamate with phenylboronic acid [8] as a function of mol \% acetic acid [relative to dirhodium(II) caprolactamate]. 


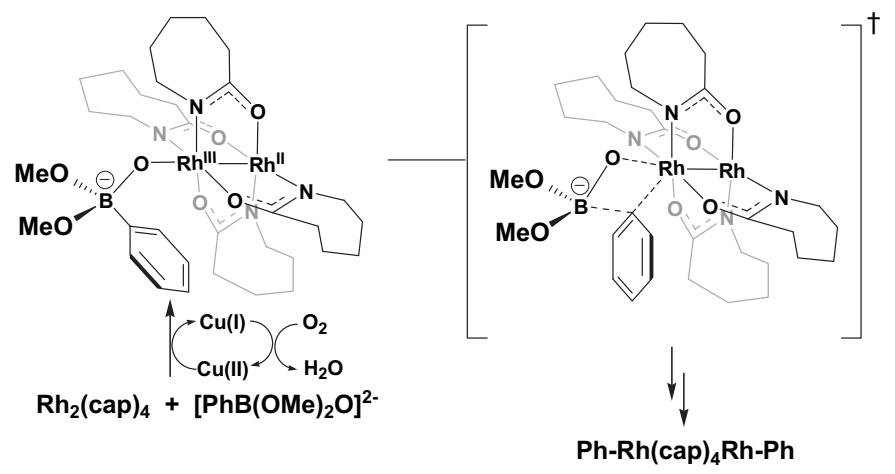

Scheme 1. Mechanism for phenyl transfer to rhodium.

$\mathbf{O}$ occurs slowly at room temperature but at an increasing rate with higher temperature and, as shown in Fig. 4, the rate of destruction of $\mathbf{O}$ is much faster than that of $\mathbf{G}$. The products of this reaction are benzene, caprolactam, and presumably one or more rhodium(III) species:

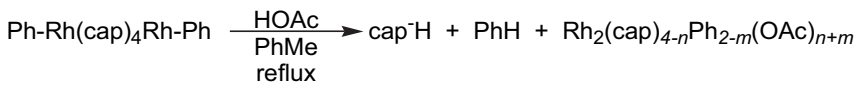

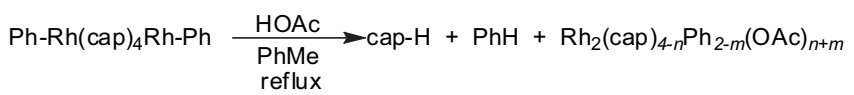

This more rapid acid promoted destruction of $\mathbf{O}$ accounts for the decrease in yield with increase in relative percentage of $\mathbf{G}$ that is seen in Fig. 3.

UV-visible spectral analyses showed that the acid promoted destruction of $\mathbf{O}$ was rapid in refluxing dichloromethane (see decrease in absorption at $430 \mathrm{~nm}$, Fig 5). However, the absorption at $430 \mathrm{~nm}$ increased for the acid promoted destruction of $\mathbf{G}$ (Fig 6). These results demonstrated that the acetic acid promoted the destruction of $\mathbf{O}$ faster than that of $\mathbf{G}$, and they indicated that acetic acid protonated the caprolactamate ligands in $\mathrm{G}$ to form a protonated-complex, which could contribute to increasing the UV-visible absorption at $430 \mathrm{~nm}$, rather than undergoing protonolysis of the benzene ring resulting in destruction of $\mathbf{G}$. No transformation between $\mathbf{G}$ and $\mathbf{O}$ took place in this process. Thus, the acid promoted formation of $\mathbf{O}$ occurs when the phenyl ring approaches rhodium in the copper-catalyzed arylation reaction (Scheme 1).

\section{Materials and Methods}

\section{General procedure for reactions of $\mathrm{PhRh}(\mathrm{cap})_{4} \mathrm{RhPh}$ with HOAc}

In each experiment $2.3 \mathrm{mg}(2.8 \mu \mathrm{mol})$ of $\mathbf{O}$ (or $\mathbf{G}$ or a $1: 1 \mathrm{mix}-$ ture of $\mathbf{O}$ and $\mathbf{G}$ ) was added to a dry sample vial followed by $0.50 \mathrm{~mL}$ (or $1.0 \mathrm{~mL}$ ) of HOAc and $5.0 \mathrm{~mL}$ DCM. The vial was

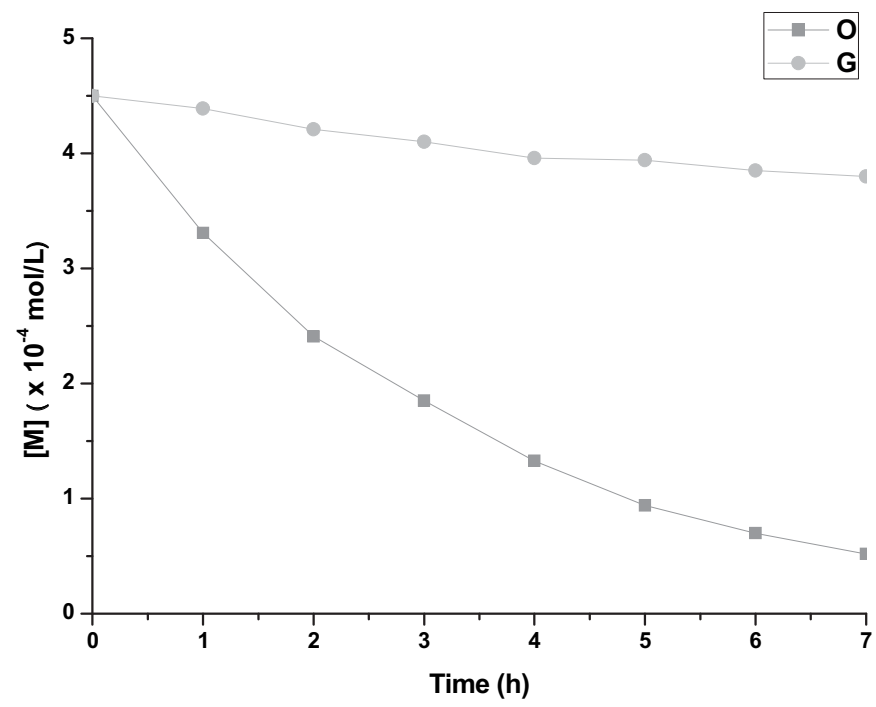

Fig. 4. Concentration of $\mathbf{O}$ and $\mathbf{G}$ as a function of time from the reaction of equal molar amounts of $\mathbf{O}$ and $\mathbf{G}$ with acetic acid (1.5 M) in refluxing dichloromethane. Progress of reaction was followed by visible spectroscopy and HPLC analysis. The first order rate constants for decomposition of $\mathbf{O}$ and $\mathbf{G}$ were $0.310 \mathrm{~h}^{-1}$ and $0.025 \mathrm{~h}^{-1}$, respectively.

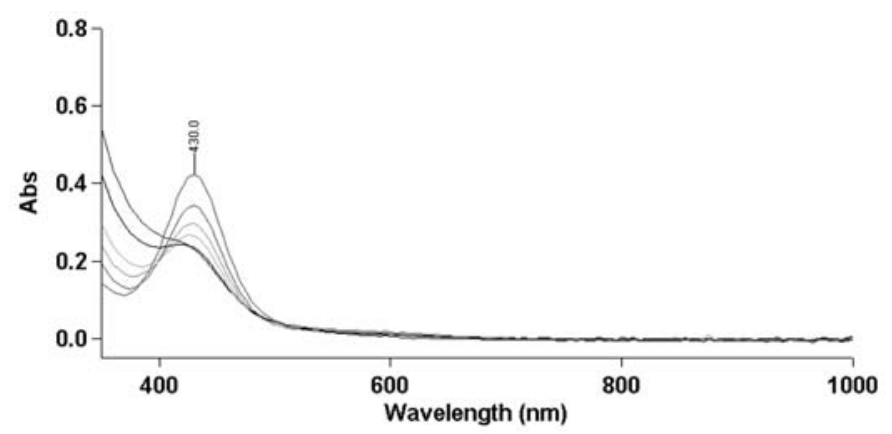

Fig. 5. Reaction of $\mathbf{O}$ with HOAc in refluxing DCM: Red line is before refluxing began, then spectra were taken at $1,2,3,5,7 \mathrm{~h}$ reflux.

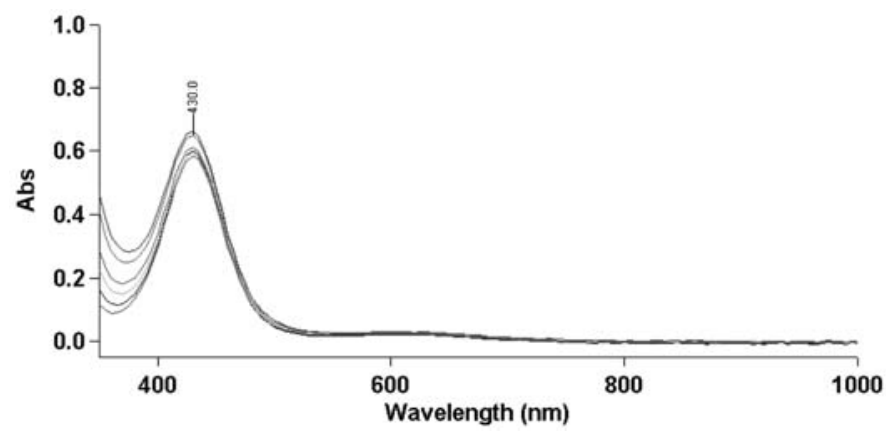

Fig. 6. Reaction of $\mathbf{G}$ with HOAc in refluxing DCM: Red line is before refluxing began, then spectra were taken at 1, 2, 3, 5, $7 \mathrm{~h}$ reflux. 
sealed with a pressure cap and heated to mild reflux with an oil bath. Samples of the reaction solution were taken at interval of 1 or $3 \mathrm{~h}$ and subjected to visible spectral and HPLC analyses. For UV-visible spectral analyses, $0.50 \mathrm{~mL}$ of the reaction solution was removed and diluted to $3.0 \mathrm{~mL}$ with DCM (see Fig. 5 and Fig. 6). For HPLC analyses $0.5 \mathrm{~mL}$ of the reaction solution was removed, $0.50 \mathrm{~mL}$ of a DCM solution containing an internal standard $\left[10 \mathrm{mg} \mathrm{ArRh}(\mathrm{cap})_{4} \mathrm{RhAr}\left(\mathrm{Ar}=4-\mathrm{MeOCOC}_{6} \mathrm{H}_{4}\right)\right.$ in $25 \mathrm{~mL} \mathrm{DCM}, 4.3 \times 10^{-4} \mathrm{mmol} / \mathrm{mL}$ ], and the resulting solution was subjected to HPLC analysis: Agilent XDB-C-18 column, $5 \mu \mathrm{m}, 4.6^{\prime} 150 \mathrm{~nm} ;{ }^{i} \mathrm{PrOH} / \mathrm{CH}_{3} \mathrm{CN}=13: 87,1.0 \mathrm{~mL} /$ $\min , 254 \mathrm{~nm}, 33$ bar. $t_{\mathrm{R}} 3.57 \mathrm{~min}$ (orange isomer), $t_{\mathrm{R}} 4.38 \mathrm{~min}$ (internal standard), $t_{\mathrm{R}} 6.89 \mathrm{~min}$ (green isomer).

\section{Synthesis of $\mathrm{PhRh}(\mathrm{cap})_{4} \mathrm{RhPh}$ from $\mathrm{Rh}(\mathrm{cap})_{4} \mathrm{Rh}$ in the presence of HOAc.}

To a dry vial was added $22.1 \mathrm{mg}(30 \mu \mathrm{mol}) \mathrm{Rh}_{2}(\mathrm{cap})_{4}\left(\mathrm{CH}_{3} \mathrm{CN}\right)_{2}$ and $6.8 \mathrm{mg}(60 \mu \mathrm{mol})$ e-caparolactam followed by a solution of HOAc in toluene, and additional toluene was added to make the total volume $5.0 \mathrm{~mL}$. The vial was sealed with a pressure cap and heated to mild reflux with an oil bath. The color of the reaction solution changed from purple to blue after reflux for 10 minutes. The reaction solution was refluxed for $4 \mathrm{~h}$, and the solvents were removed under reduced pressure to provide a purple or blue residue. Then $18.3 \mathrm{mg}(150 \mu \mathrm{mol})$ of phenylboronic acid and $25.2 \mathrm{mg}(300 \mu \mathrm{mol})$ of sodium bicarbonate were added, followed by $4 \mathrm{~mL} \mathrm{DCM}$, and the mixture was stirred at room temperature. After stirring for a few minutes, $1.0 \mathrm{~mL}(3 \mu \mathrm{mol} / \mathrm{mL}, 3 \mu \mathrm{mol})$ of $\mathrm{CuSO}_{4} .5 \mathrm{H}_{2} \mathrm{O}$ in $\mathrm{MeOH}$ was added, and the resulting solution was stirred at room temperature for $18 \mathrm{hrs}$. The solvents were removed under reduced pressure, and the residue was chromatographed on silica gel with DCM as the eluent. All of the colored materials were collected and subjected to HPLC analyses. HPLC conditions: Agilent XDB-C-18 column, $5 \mu \mathrm{m}, 4.6 \times 150 \mathrm{~nm}$; ${ }^{i} \mathrm{PrOH} / \mathrm{CH}_{3} \mathrm{CN}=13: 87,1.0 \mathrm{~mL} / \mathrm{min}, 254 \mathrm{~nm}, 33$ bar. $t_{\mathrm{R}} 3.57$ $\min$ (orange isomer), $t_{\mathrm{R}} 6.24 \mathrm{~min}$ (minor green isomer), $t_{\mathrm{R}}$ $6.89 \mathrm{~min}$ (green isomer).

\section{Conclusion}

In our search for the possible cause of the formation of noninterconvertable propeller (O) and biplanar (G) conforma- tional isomers of bisphenyldirhodium(III) caprolactamate we have found that the formation of the minor conformational isomer is promoted by the presence of residual acetic acid in the reaction mixture during and/or prior to the oxidative coupling reaction with phenylboronic acid that is catalyzed by copper(II). Furthermore, the propeller conformer (O) is found to decompose at a rate that is more than ten-times faster than that for the biplanar conformer (G). These findings provide the first examples of acid-promoted differentiation in the formation and decomposition of conformational isomers.

\section{Acknowledgments.}

We are grateful to the National Science Foundation of the United States for their support of this research.

\section{References}

1. Conformational Analysis, ed. by Eliel, E.; Allinger, N. L.; Angval, S. J.; Morrison, G. A., Wiley Interscience, New York, 1965).

2. Eliel, E. L.; Wilen, S. H. Stereochemistry of Organic Compounds Wiley, New York, 1994.

3. Eliel, E. L.; Wilen, S. H.; Doyle, M. P. Basic Organic Stereochemistry Wiley, New York, 2001.

4. D. Timmons, D.; Doyle, M. P. In Metal Bonds Between Metal Atoms, Third Edition, ed. by Cotton, F. A.; Murillo, C. A.; Walton, R. A., Springer Science and Business Media, New York, 2005, Chapter 13.

5. Doyle, M. P.; Ren, T. In Progress in Inorganic Chemistry, Vol. 49, ed. by Karlin, K. Ed., John Wiley \& Sons, Inc., New York, 2001.

6. Doyle, M. P. J. Org. Chem. 2006, 71, 9253 - 9260.

7. Nichols, J. M.; Wolf, J.; Zavalij, P.; Varughese, B.; Doyle, M. P. J. Am. Chem. Soc., 2007, 129, 3504 - 3505.

8. Xie, J.-H.; Nichols, J. M.; Lubek, C.; Doyle, M. P. Chem. Commun. 2008, 2671 - 2673.

9. Wolf, J.; Poli, R.; Xie, J.-H.; Nichols, J.; Xi, B.; Zavalij, P.; Doyle, M. P. Organometallics, 2008, 27, 5836 - 5845.

10. Xie, J.-H.; Zhou, L.; Zavalij, P.; Doyle, M. P.; Sun, Y.; Liu, Y.; Sun, H. Chem. Commun. 2009, 3505 - 3507 .

11. Chifotides, H. T.; Dunbar, K. R. in Metal Bonds Between Metal Atoms, Third Edition, ed. by Cotton, F. A.; Murillo, C. A.; Walton, R. A., Springer Science and Business Media, New York, 2005, Chapter 12.

12. Doyle, M. P.; Westrum, L. J.; Wolthuis, W. N. E.; See, M. M.; Boone, W. P.; Bagheri, V.; Pearson, M. M. J. Am. Chem. Soc. 1993, 115,958 - 964. 